\title{
Barriers and Enablers to Buying Biodegradable and Compostable Plastic Packaging
}

\author{
Ayşe Lisa Allison ${ }^{1,2, *(D)}$, Fabiana Lorencatto ${ }^{2}$, Susan Michie ${ }^{1,2}$ and Mark Miodownik ${ }^{1}$ (D) \\ 1 UCL Plastic Waste Innovation Hub, University College London, London WC1E 6BT, UK; \\ s.michie@ucl.ac.uk (S.M.); m.miodownik@ucl.ac.uk (M.M.) \\ 2 UCL Centre for Behaviour Change, University College London, London WC1E 6BT, UK; \\ f.lorencatto@ucl.ac.uk \\ * Correspondence: ayse.allison.18@ucl.ac.uk
}

Citation: Allison, A.L.; Lorencatto, F.; Michie, S.; Miodownik, M. Barriers and Enablers to Buying Biodegradable and Compostable Plastic Packaging. Sustainability 2021, 13, 1463. https://doi.org/10.3390/ su13031463

Academic Editor: Antonino Galati

Received: 26 November 2020

Accepted: 22 January 2021

Published: 30 January 2021

Publisher's Note: MDPI stays neutral with regard to jurisdictional claims in published maps and institutional affiliations.

Copyright: (c) 2021 by the authors. Licensee MDPI, Basel, Switzerland. This article is an open access article distributed under the terms and conditions of the Creative Commons Attribution (CC BY) license (https:// creativecommons.org/licenses/by/ $4.0 /)$.
Abstract: Biodegradable and compostable plastic packaging (BCPP) has the potential to reduce a global plastic waste problem. We aimed to identify influences on buying BCPP as a basis for designing strategies that enable BCPP's environmental benefits. Using a UK-focused citizen science dataset, we thematically analysed 610 survey responses to a question exploring reasons for BCPP purchase. Themes are categorised as barriers and enablers and according to the components of the Capability, Opportunity, Motivation, and Behaviour (COM-B) model of behaviour. Key barriers concerned: psychological capability (not understanding terminology used to label packaging, not taking notice of packaging, and preferring other types of packaging and product qualities); reflective motivation (negative beliefs about BCPP's environmental impacts and skepticism over decomposition claims), and physical opportunity (no access to appropriate waste management). Key enablers concern: reflective motivation (positive beliefs about $\mathrm{BCPP}^{\prime}$ s environmental impact and resolve to behave pro-environmentally) and physical opportunity (access to appropriate waste management). Reducing ambiguity concerning the labels of biodegradable and compostable may reduce skepticism over environmental claims of packaging. Interventions should improve information about the source of the packaging material, how the packaging waste is processed, and how to dispose of the packaging. This will not be sufficient unless facilities for local BCPP waste collection and processing are increased.

Keywords: biodegradable plastic; compostable plastic; plastic packaging; plastic waste; behaviour change; circular economy; citizen science; COM-B; sustainability; consumer behaviour

\section{Introduction}

The growing accumulation of plastic waste is a global health and sustainability threat. In 2018, global plastics production reached nearly 360 million tons, approximately $40 \%$ of which was used in packaging applications [1]. Single-use packaging plastics have a number of health and environmental benefits within global supply chains e.g., facilitating clean drinking water and food hygiene/safety, reducing food waste, and reducing packaging weight during transportation [2-4]. However, large amounts of plastic have leeched into the natural environment with detrimental consequences. The accumulation of plastic within marine habitats results in the disruption of various ecological processes and harm to marine and aquatic species' health [5-9]. On land, disruptions of soil ecosystems and the risk of groundwater pollution have been identified [10]. In addition, plastic particles and fibres have been found in tap water, beer, and salt [11,12], and have accumulated within the food chain $[13,14]$, where the health risks posed by human ingestion are not yet fully understood. As packaging represents the largest end-use market of plastic and is the dominant generator of plastic waste [1,15], interventions within the packaging industry are an avenue to reducing the amount of plastic waste generated. Biodegradable and compostable plastics are one such example. The challenge with conventional flexible and semi-flexible plastic packaging (e.g., bags, pouches, film, and tubes typically for residential 
use), which makes up $17 \%$ of all plastic packaging placed on the market [16], is that they are currently technically difficult to recycle, and it is not currently economically viable to do so [17]. Biodegradable and compostable plastics, particularly within flexible plastic packaging applications, represent a key opportunity for reducing the harmful health, environmental, and societal impacts of plastic waste without compromising the operations of supply chains. However, these environmental benefits are only enabled if BCPP is correctly disposed of by the end user (e.g., putting in the correct bin) and appropriately managed post-consumer (e.g., collected into the appropriate waste stream and processed in the appropriate conditions for biodegradation) [18].

There is a growing body of technical research with respect to biodegradable and compostable plastics, including investigations into their degradation processes $[19,20]$ and life cycle assessments $[21,22]$. However, research into the impact of human behaviour in relation to producing, consuming, and disposing of plastics is lacking. In particular, our knowledge regarding the influences on the purchase, use, and disposal of biodegradable and compostable plastic packaging (BCPP) is limited. There has been some research into citizens' knowledge, preferences, and perceptions in relation to BCPP. For instance, evidence shows that Italian citizens prefer biodegradable plastic water bottles over traditional PET plastic bottles, and are willing to pay a premium for them [23]. A 2007 UK study of perceptions towards biopolymers found that, although citizens felt positively towards biodegradable plastics, awareness of these products on the market and knowledge of what they are was low [24]. Similar results were reported by a more recent survey of Australian citizens, showing that people incorrectly dispose of biodegradable plastics [25]. These findings are supported by an experiment investigating the rate of correct disposal for biodegradable plastic water bottles vs. recyclable plastic water bottles in Germany [26]. Although German citizens reported positive attitudes towards biodegradable plastic packaging, they frequently disposed of them incorrectly, thus, undermining their environmental benefits [26]. Since these studies do not use behaviour change theory, their application in designing behaviour change interventions is limited. More comprehensive understanding of behaviour is needed to design such strategies effectively.

Plastic waste is the product of certain behaviours enacted by various key actors (e.g., citizens, producers, retailers, and policy makers) within the system of plastic (i.e., fabrication, supply, use, and waste collection/processing). Behaviour change will, therefore, be a key component of any solution. A pre-requisite for designing behaviour change interventions that are likely to be effective will be identifying the key behavioural targets that need to change in order to increase behaviours that reduce waste and decrease behaviours that lead to waste.

Citizen behaviours are a central part of the plastics system, since they include buying, using, and disposing of packaging (we use the term citizen rather than consumer, as this term only allocates an economic role as a buyer of goods, not the role of sorting and correctly disposing of packaging). It is important that BCPP is not only viable from an economic and technical perspective, but also that citizens' behaviours enable their environmental benefits. To design interventions that change citizen behaviours to reduce plastic packaging waste, it will be necessary to understand the influences on them. Focusing on purchasing behaviour is a useful starting point, as it is the initial behaviour in a chain of behaviours the citizen will need to enact when interacting with BCPP.

The behavioural sciences offer a range of theory- and evidence-based approaches to facilitate the process of identifying behavioural influences. One such integrated model of behaviour change is the COM-B model of behaviour (Capability, Opportunity, Motivation, and Behaviour; see Figure 1) $[27,28]$. The COM-B model posits that for a behaviour to occur, there must be capability, opportunity, and motivation to enact the behaviour. Capability refers to aptitude or ability, and can be further broken down into two subcomponents: physical capability (e.g., physique and stamina) and psychological capability (e.g., memory and decision-making processes). Opportunity refers to the environmental context, and can be broken down into social opportunity (e.g., the social environment of 
cultures and norms) and physical opportunity (e.g., the physical environment of objects and events with which people interact). Motivation refers to the processes that initiate and guide behaviour, and can be broken down into automatic motivation, which refers to psychological processes largely out of conscious control (e.g., emotions, habits, and instincts) and reflective motivation, which refers to the conscious psychological processes that energise and direct behavior (e.g., intentions and evaluations).

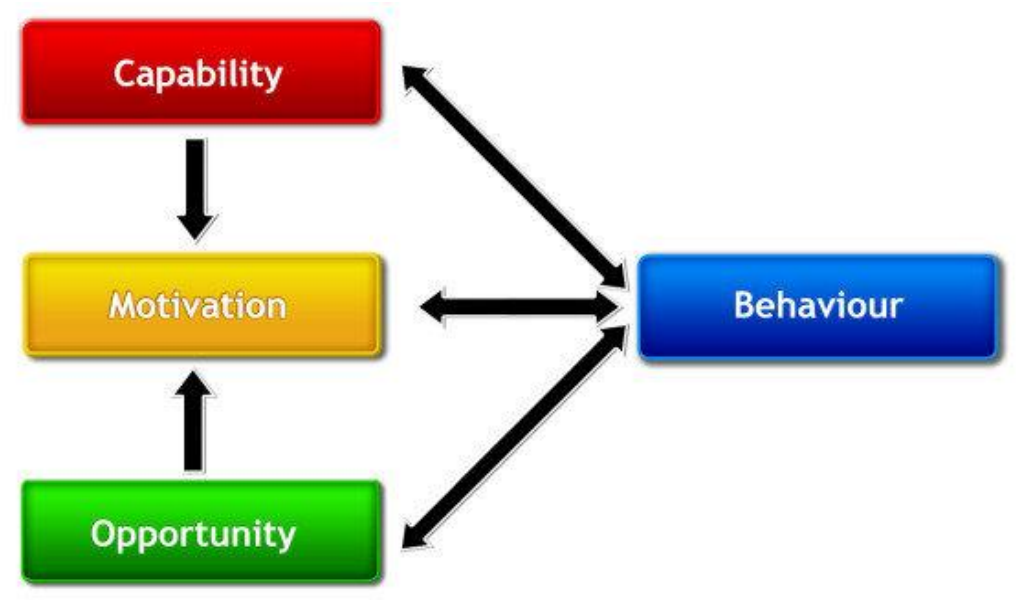

Figure 1. The COM-B model-a framework for understanding behaviour.

The COM-B model provides a useful framework for identifying the various individual, socio-cultural, and situational influences on a behaviour, and has previously been applied to understanding environmentally significant behaviours, e.g., food consumption [29,30], water conservation [31], and recycling [32]. However, its application within the sustainability context remains limited, particularly in understanding human citizen behaviour with respect to $\mathrm{BCPP}$.

A citizen science study aimed at understanding the public's views, knowledge, and behaviours relating to the use of BCPP, The Big Compost Experiment, has been conducted in the UK [33]. Details on citizen science as a research method can be found elsewhere [34-36]. The project consists of a publicly accessible website containing an online survey regarding current composting practices, BCPP purchasing behaviour, and an optional BCPP home composting experiment. In this study, we aim to understand the influences (i.e., barriers and enablers) on people's purchasing of BCPP as a basis for intervention development. To this end, our research question is: what are the barriers and enablers, in terms of capability, opportunity, and motivation, to buying BCPP?

\section{Methods}

\subsection{Design}

This was a cross-sectional survey study.

\subsection{Participants and Recruitment}

Study participants consisted of adults, aged 18 and above, within the general UK population, across all regions. Demographic information about survey respondents was not collected. The project was advertised via the following channels: email (including UCLaffiliated mailing lists), social media (including the authors' social and professional social media networks), interviews on national and regional radio (including BBC Radio 4 Inside Science, Cambridge 105), articles in national charity and organisation magazines (including Science World, National Allotment Society, and Garden Organic), and public outreach events within London (including the 2019 Bloomsbury Festival). Prospective participants were directed to The Big Compost Experiment website containing the survey link. 


\subsection{Measures}

The survey instrument is openly available via Open Science Framework (OSF) at https://doi.org/10.17605/OSF.IO/F7JNS. The survey was designed by researchers at UCL's Plastic Waste Innovation Hub [37]. It contains questions that investigate: (a) participants' reasons for buying or not buying BCPP; (b) whether participants separate their food waste and, if not, their reasons for not doing so and; and (c) whether participants home compost and, if so, which composter they use, what materials they put in their compost, and which organisms they have noticed in their compost heap.

A theoretical framework was not used to design questions investigating behavioural influences in order to elicit responses in an unbiased and unprompted manner. Survey items investigating the types of organic waste placed in compost bins and the types of organisms identified in compost were based on a prior citizen science experiment conducted by Garden Organic [38] and educational resources available via the Soil Food Web [39].

For this study, we were interested in the responses to one question within the larger survey: the first question, which asked whether people were likely to buy BCPP (i.e., "Are you more likely to buy products with packaging marked 'compostable' or 'biodegradable'?"). Participants had options of answering yes, no, or I don't know, and had to provide a reason for their answer in free text form.

\subsection{Procedure}

Ethical approval was received from UCL (Project ID/Title: 16747/001: Big Compost Experiment). The survey was accessed via an online web link, and took approximately five minutes to complete. Participants were asked to give informed consent prior to completing a short survey, and were given a link to the study information sheet. They were then invited to take part in an optional home composting experiment, where they could create a profile and upload photos tracking the degradation process of $\mathrm{BCPP}$ in their composters.

\subsection{Data Analysis}

We conducted a qualitative secondary analysis [40] of survey responses from The Big Compost Experiment citizen science project. The Big Compost Experiment is an ongoing project; this study analyses cross-sectional survey responses collected from November 2019 to March 2020. The dataset analysed in this study is openly available via OSF at https:/ / doi.org/10.17605/OSF.IO/F7JNS. Data were analysed within Excel.

In line with McGowan, Powell, and French's guidance [41] for assessing behavioural determinants in qualitative studies, we took an inductive approach to analysis first, followed by deductive theory-based analysis as a second step. The authors use the Theoretical Domains Framework (TDF), as opposed to COM-B, to illustrate the merits of this approach. However, the principles extend to COM-B, as they are associated frameworks. Each component of the COM-B model can be elaborated into the various TDF domains, making TDF a more granular expansion of COM-B $[27,42,43]$. COM-B is, therefore, also a relevant and appropriate model to use via this approach.

For the inductive analysis, we conducted a thematic analysis [44] on 200 random free text responses from yes responders, 205 free text responses from no responders, and 205 free text responses from I don't know responders to the question: "Are you more likely to buy products with packaging marked 'compostable' or 'biodegradable'?" Respondents that did not provide a complete answer to this item were excluded from the analysis.

For the deductive theory-based analysis, we used COM-B as a data analysis framework to organise emergent themes as behavioural influences related to capability, opportunity, and motivation. As detailed in Figure 2, our analysis was conducted in the following steps:

1. Familiarisation with the data. This involved reading all survey responses and noting any recurring patterns.

2. Generation of initial codes to indicate themes. As responses were assigned codes, a coding framework detailing code labels and definitions was developed and revised iteratively to help guide subsequent coding. 
3. Search for themes. This involved organising codes into a tentative set of candidate themes.

4. Review of themes. This step involved a back-and-forth process of revisiting the raw survey responses and coding framework in order to update the names, descriptions, and definitions of candidate themes.

5. Mapping of emergent themes onto COM-B categories of barriers and enablers. A theme qualified as a barrier if it deterred the purchasing of BCPP, as an enabler if it promoted it, and as mixed if it could do both. Theme labels and their categorisation into COM-B components was reviewed by a co-investigator (FL), upon which the appropriate revisions were made.

6. Assignation of names and definitions for themes. This involved finalising the name, definition, description, and example quotes for each theme. The coding framework in Appendix B shows each theme's names, definitions, descriptions, and example quotes grouped according to those who said they were more likely, unlikely, or unsure whether they would buy BCPP.

7. Production of the report. This involved writing up the analysis with feedback from co-investigators.

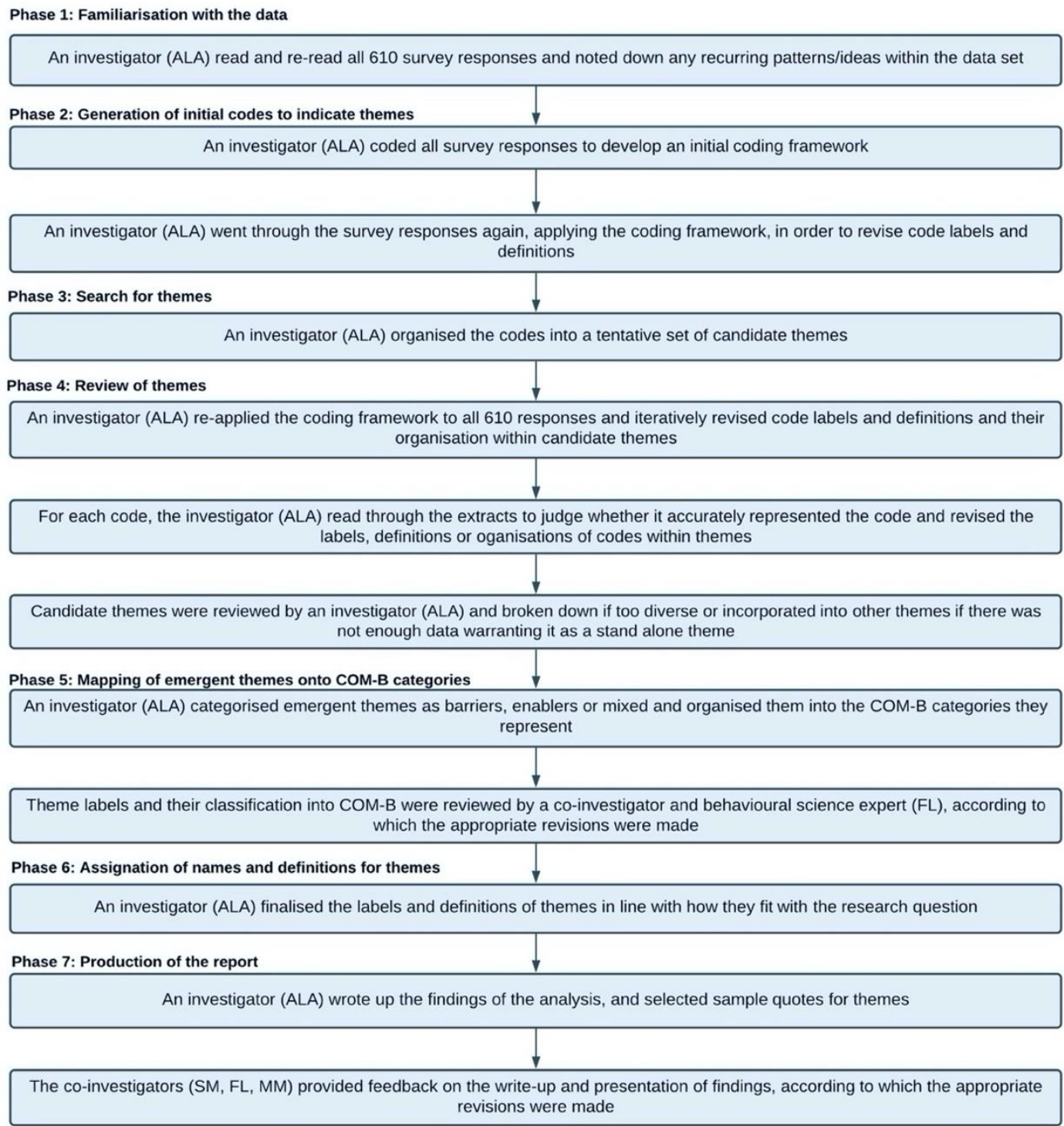

Figure 2. The steps undertaken to create the thematic analysis. 
Guidance on conducting thematic analyses can be found elsewhere [45,46]. The Thematic Codebook in Supplementary Table S1 shows each theme's name, definition, description, and example quotes grouped according to those who said they were more likely, unlikely, or unsure whether they would buy BCPP. Thematic data saturation was assessed after the 610th participant to justify discounting data analysis [47-49]. Guidance on assessing data saturation can be found elsewhere [50].

\subsection{Interpretation of the Results}

Emergent themes from the analysis are presented as bullet points in the Results section. Themes have been presented as barriers and enablers to buying BCPP, and organised according to components of the COM-B model. The descriptions underneath each bullet point provide an explanation of the emergent theme. The frequencies included in Table 2 show how many participants reported that given theme, and are included to highlight the relative weight and importance of each theme.

\section{Results}

A total of 6523 participants responded to the survey. After removing participants who did not provide a reason for their answer to the question "Are you more likely to buy products with packaging marked 'compostable' or 'biodegradable'?", 5176 participant responses remained. Of these, the majority of the respondents indicated that they were more likely to buy products in BCPP $(84.1 \%), 8.1 \%$ said they were not, and $7.8 \%$ said they were unsure (Table 1).

Table 1. The frequency and percentage of respondents indicating whether they were more likely to opt for BCPP.

\begin{tabular}{ccc}
\hline Answer & Frequency (Total = 5176) & Percentage (\%) \\
\hline Yes & 4353 & 84.1 \\
No & 419 & 8.1 \\
I don't know & 403 & 7.8 \\
\hline
\end{tabular}

There were no new themes after the 610th participant (see Data Saturation Table, Supplementary Table S2). Enablers were reported only by those who indicated that they were likely to buy BCPP. Barriers were reported by those who said they were likely, unlikely, and unsure whether they would buy BCPP, with some barriers (i.e., understanding terminology and labels, packaging preferences) reported across all groups. Frequencies and illustrative quotes for barriers and enablers are shown in Table 2. Quotes from participants are included alongside their survey IDs.

Table 2. Frequencies and illustrative quotes for each theme mapped to COM-B categories.

\begin{tabular}{|c|c|c|c|c|}
\hline $\begin{array}{l}\text { COM-B } \\
\text { Domain. }\end{array}$ & Theme $(n=16)$ & $\begin{array}{l}\text { No. (Max } \\
n=112)\end{array}$ & $\begin{array}{l}\text { Barrier/ } \\
\text { Enabler }\end{array}$ & Example Quote(s) \\
\hline \multirow[b]{3}{*}{ Psych. Cap. } & $\begin{array}{l}\text { 1. Understanding } \\
\text { terminology/labels }\end{array}$ & 61 & Barrier & $\begin{array}{l}\text { "I am not sure what these terms really mean." ID } 17551 \\
\text { "These terms are confusing and can misleading." } \\
\text { ID } 13113\end{array}$ \\
\hline & $\begin{array}{l}\text { 2. Awareness of plastic } \\
\text { waste problem }\end{array}$ & 4 & Enabler & $\begin{array}{l}\text { "I am aware of the crisis with plastic around the world } \\
\text {..." ID } 21563\end{array}$ \\
\hline & $\begin{array}{l}\text { 3. Attention to product } \\
\text { packaging and labelling }\end{array}$ & 55 & Barrier & $\begin{array}{l}\text { "I don't always notice the compostable/biodegradable } \\
\text { signs amongst other text, images, and symbols on } \\
\text { packaging." ID } 18872 \\
\text { "Don't read labels when shopping." ID } 21986 \\
\text { "Partly forget to check. Only look at the packaging when } \\
\text { I come to put it in the bin." ID } 15122\end{array}$ \\
\hline
\end{tabular}


Table 2. Cont.

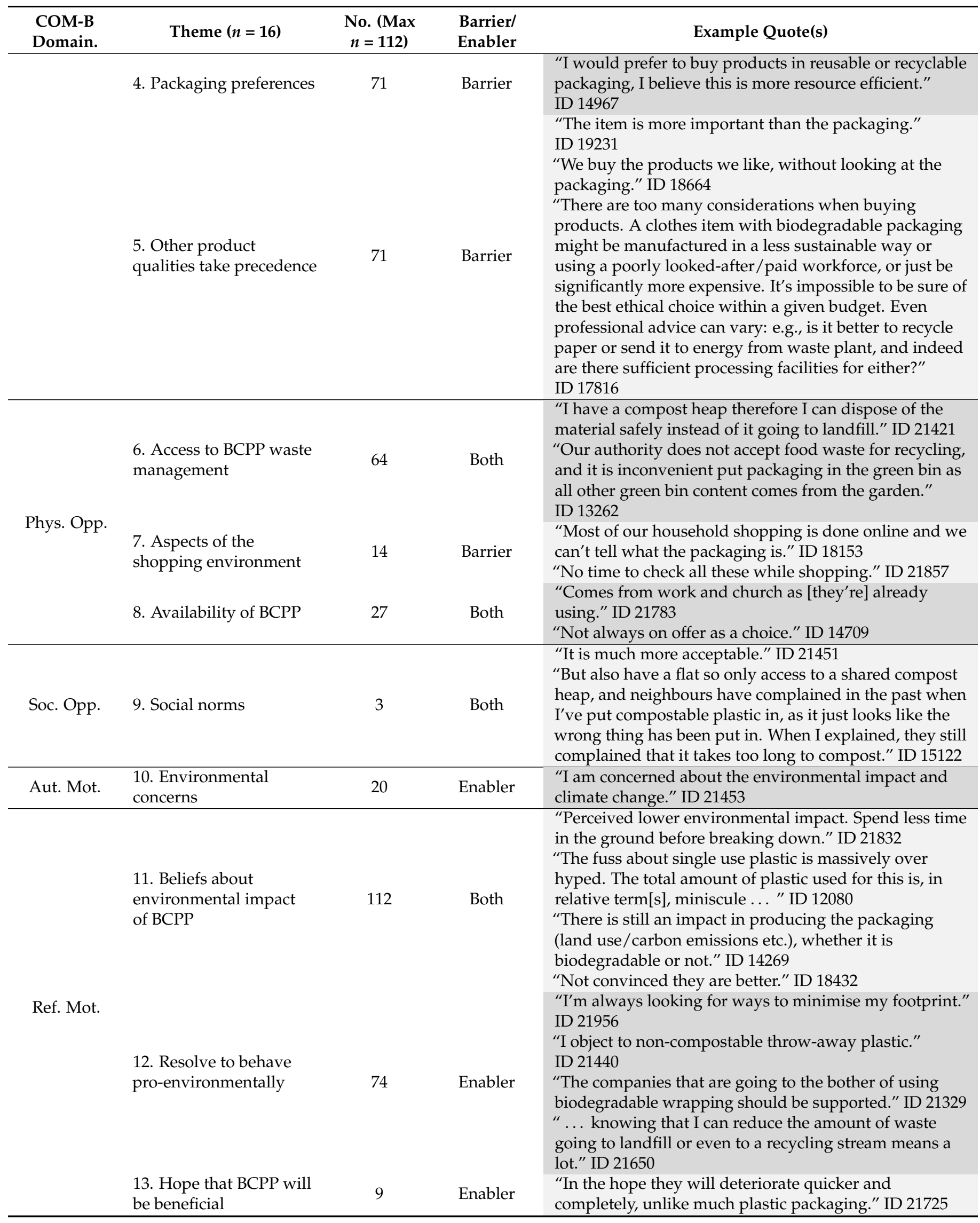


Table 2. Cont.

\begin{tabular}{|c|c|c|c|c|}
\hline $\begin{array}{l}\text { COM-B } \\
\text { Domain. }\end{array}$ & Theme $(n=16)$ & $\begin{array}{c}\text { No. (Max } \\
n=112)\end{array}$ & $\begin{array}{l}\text { Barrier/ } \\
\text { Enabler }\end{array}$ & Example Quote(s) \\
\hline & $\begin{array}{l}\text { 14. Skepticism over } \\
\text { decomposition claims }\end{array}$ & 112 & Barrier & $\begin{array}{l}\text { "I would buy if the compostability was deliverable-not } \\
\text { just greenwashing as it is at present." ID } 21167 \\
\text { "Having put 'biodegradable' stuff in my compost bins in } \\
\text { the past they don't seem to break down very effectively." } \\
\text { ID } 18820\end{array}$ \\
\hline & $\begin{array}{l}\text { 15. No intention to buy } \\
\text { BCPP }\end{array}$ & 33 & Barrier & $\begin{array}{l}\text { "I try to buy products with absolutely minimal } \\
\text { packaging or better none at all." ID } 18164 \\
\text { "I would be unlikely to purchase them and remain with } \\
\text { taking my own bags to fill with my fruit and veg and } \\
\text { re-useable coffee cup." ID } 14267 \\
\text { "Because I can't be bothered to read every bit of } \\
\text { packaging." ID } 12288\end{array}$ \\
\hline & $\begin{array}{l}\text { 16. Beliefs about } \\
\text { capability }\end{array}$ & 4 & Barrier & $\begin{array}{l}\text { "All manufacturers should be using these types of } \\
\text { packaging. It should not be the consumer who has to } \\
\text { check." ID } 18714 \\
\text { "I'm not the primary purch[aser]." ID } 18381\end{array}$ \\
\hline
\end{tabular}

\subsection{Barriers}

\subsubsection{Psychological Capability}

- Understanding terminology and labels

Participants reported issues with understanding the terminology used to label BCPP, for instance, not knowing what the terms biodegradable and compostable mean (e.g., "I would need a convincing explanation of what these terms meant if I were to be influenced by them ... " ID 11866), the environmental implications of the terms being vague (e.g., "I don't think it's clear whether there are lower or higher carbon emissions associated with these products." ID 18000), and a lack of knowledge regarding end-of-life instructions, including not knowing where to put the waste, not knowing what waste collection options are offered by the council, and a lack of awareness of composting as a plastic waste disposal strategy (e.g., " ... although I understand what compostable means, had not thought of it as an option ... " ID 16827). Even amongst participants who indicated that they were likely to purchase $\mathrm{BCPP}$, there was misunderstanding regarding end-of-life instructions and the environmental benefits conveyed by labels of biodegradable and compostable (e.g., "It needs to be made clearer if hot composting is required though ... " ID 21608; "Although I'm not sure which is better for the environment, I think it is the former, especially as there seems to be so many questions about what actually happens to recycled plastic ..." ID 21520).

\section{- Packaging preferences}

Preference for other types of packaging was also a barrier, and was reported by those who said they would buy, would not buy, and were unsure about whether they would buy BCPP. Preferences for packaging varied; some expressed preference for no packaging, others for recyclable and reusable materials, such as paper and glass, and others for packaging labelled as compostable over biodegradable and, more specifically, preferred home compostable over industrially compostable.

- Other product qualities taking precedence

For some participants, other aspects of a purchase were deemed more important than packaging. These included: the product itself (e.g., "It is the product that I buy, not the wrapping." ID 17563), price (e.g., "My main incentive is price." ID 19429), other ethical attributes (e.g., " .. I try to buy fair-trade, organic, and local ... " ID 19076), and functionality (e.g., "Compostable plastic is the worst of both worlds ... it falls apart if you make it useful as a bag to hold stuff in ... " ID 20899). 
- Attention to product packaging and labelling

Those who were unsure and unlikely to buy this packaging reported not noticing or considering packaging labels, labels not being obvious or clear, and packaging being considered at the point of disposal as opposed to the point of purchase.

\subsubsection{Physical Opportunity}

- Aspects of the shopping environment

For those who said they would not buy or were unsure about buying BCPP, barriers related to the physical commercial environment, for instance, the lack of packaging information when shopping online and time constraints while shopping.

- Access to BCPP waste management

For those that would not buy or were unsure about buying BCPP, access was a barrier, either because their council did not offer collection or they could not compost at home.

- Availability of BCPP

This was a barrier for those without access to BCPP in their environment.

\subsubsection{Social Opportunity}

\section{- Social norms}

Social influence discouraging the purchase of BCPP was a barrier. For instance, participants mentioned tensions arising with neighbours if they put plastic in a communal compost heap (e.g., "But [I] also have a flat so only access to a shared compost heap, and neighbours have complained in the past when I've put compostable plastic in, as it just looks like the wrong thing has been put in. When I explained, they still complained that it takes to[o] long to compost." ID 15122).

\subsubsection{Reflective Motivation}

- Beliefs about the environmental impact of BCPP

This was a barrier for those who said they were unlikely to buy and unsure about buying BCPP. This theme included beliefs that the impact of single-use plastic is exaggerated, that biodegradable and compostable plastics have a higher carbon footprint than non-biodegradable and non-compostable plastics, and that biodegradable and compostable plastics, like traditional plastic, will also only break down into harmful microplastics.

- Skepticism over decomposition claims

This was a barrier for those who said they were unlikely to buy and not sure they would buy BCPP. For instance, some reported a general mistrust of BCPP degradation claims, while others had unsuccessfully tried to compost BCPP at home.

- No intention to buy BCPP

This theme emerged for those who said they were unsure about buying or unlikely to buy $\mathrm{BCPP}$, and included: avoiding packaging altogether, preferring to engage in other behaviours to reduce waste, and having competing priorities.

- Beliefs about capability

This emerged for those who said they were unsure whether they would buy BCPP. They perceived the producer to have responsibility for reducing plastic waste, rather than the general public, and reported not having control over household shopping e.g., because one's partner was the primary shopper.

\subsection{Enablers}

3.2.1. Psychological Capability

- Awareness of plastic waste problem

An awareness of issues with plastic waste enabled the purchase of BCPP. 


\subsubsection{Physical Opportunity}

- Access to BCPP waste management

This was an enabler for those that said they would buy BCPP, either because they already compost or their council offers collection of BCPP.

- Availability of BCPP

Having BCPP available within the commercial environment was an enabler.

\subsubsection{Social Opportunity}

\section{- Social norms}

Social norms encouraging the purchase of BCPP was an enabler. For instance, participants mentioned it being more civilized and socially acceptable to buy BCPP (e.g., "More civilised to do so." ID 21834).

\subsubsection{Automatic Motivation}

- Environmental concern

Enablers included concerns about environmental well-being, the accumulation of waste in the natural environment, and the build-up of plastic waste in particular.

\subsubsection{Reflective Motivation}

- Beliefs about the environmental impact of BCPP

This was an enabler for those who said they were likely to buy BCPP. For instance, this included beliefs that $\mathrm{BCPP}$ is more resource efficient, reduces the amount of waste sent to landfill and incineration, improves soil quality, prevents the build-up of plastic in the environment, and degrades faster than non-biodegradable plastic.

- Hope that BCPP will be beneficial

The theme of hope/optimism that BCPP will have positive environmental consequences emerged as an enabler. Here, we refer to an optimistic desire for a specific outcome that emerged distinctly from beliefs about the truth regarding BCPP's impact.

- Resolve to behave pro-environmentally

This resolve included an intention to support businesses that use BCPP and wanting to buy BCPP, as it aligns with one's ethos or values.

\section{Discussion}

The main reasons for people buying $\mathrm{BCPP}$ concerned reflective motivation (positive beliefs about BCPP's environmental impact and resolve to behave pro-environmentally) and physical opportunity (access to appropriate waste management). Key reasons for not buying BCPP concerned psychological capability (not understanding the terminology used to label packaging, not taking notice of packaging, and preferring other types of packaging and product qualities), reflective motivation (negative beliefs about BCPP's environmental impacts and skepticism over decomposition claims), and physical opportunity (no access to appropriate waste management).

Our results are in line with previous findings. Having pro-environmental values and intentions increase the purchase of eco-products, therefore, it is unsurprising that they impact BCPP purchase as well [51,52]. Environmental concern, social influences, and awareness of environmental issues promote the consumption of eco-friendly products and services [53-55]. Our results suggest that these factors also extend to the purchase of BCPP.

Our findings support a lack of knowledge as a barrier to buying BCPP [56]. Previous results show that people may not understand eco labels as intended, or be aware that they even exist $[57,58]$. This is consistent with our findings that packaging labels often go unnoticed, and that people do not know what biodegradable and compostable mean 
in terms of their environmental impact and disposal instructions, even amongst those who are willing and motivated to purchase BCPP. A preference for home compostable packaging over biodegradable or industrially compostable packaging was found. This could be related to greater clarity regarding end-of-life options for the term compostable over biodegradable. Further research is needed to clarify this.

Misunderstanding the terminology on labels can negatively impact citizens' perceptions of sustainable products, leading to skepticism and mistrust [57,59]. Our findings support this, as participants shared negative beliefs about BCPP and skepticism over biodegradability claims. This may reflect the fact that the term biodegradable is often misused when describing packaging [60], despite definitions being available (Dir2019/904; [61]).

Our findings also support the role of citizen preferences in influencing packaging purchase. Participant preferences for no packaging or non-plastic packaging materials, such as paper and glass, are echoed in a similar study of Romanian citizens [56]. While environmentally friendly packaging may be favoured in principle, factors like brand, price, and convenience can override its importance [62]. Consuming sustainably may also be experienced by people as stressful, time-consuming, and too expensive [63]. Our results support this, as price was reported as an influence on buying BCPP. Our participants also reported feeling overwhelmed when trying to evaluate the environmental friendliness of products.

Structural changes within the immediate commercial environment could address the identified barriers of limited BCPP availability and the lack of packaging information when shopping online. Retail outlets are the mediators between citizens and products: through providing information, incentivizing, and orienting customers towards eco-products, they can increase sustainable purchasing behaviours [64]. Not noticing product packaging and labels was identified as an influence on purchasing, which could also be addressed through structural design changes that orient people towards BCPP.

The environmental influences found to be effective in influencing waste management behaviours extend to buying BCPP. For instance, recycling rates are influenced by having the appropriate bins at home [65] and by local curb-side recycling schemes [66]. The varied experiences of our participants highlight the lack of a UK-wide system of collecting and processing BCPP [67]. This undermines the environmental benefits, as BCPP risks being littered or contaminating other waste streams.

Our analysis suggests that a labelling system that enables the appropriate purchase and waste management behaviours is needed, alongside improvements to BCPP waste collection and processing. Preliminary results already show that designing food packaging based on user-centered needs may promote more desirable waste disposal behaviours [68]. To promote the purchase of BCPP, environmental impacts need to be better communicated on packaging. Ecolabelling is a key tool for promoting sustainable purchases, but will only work if people are engaged, informed, and trusting of packaging claims [57]. Gaining citizens' trust will rely on a more consistent and transparent method of manufacturing, labelling, and testing BCPP. Developments in infrastructure will be needed for introducing a nation-wide collection and processing system for BCPP, ensuring that the public can put the right materials in the right (compost) bin for the appropriate waste processing. This could, for instance, include adapting current food waste or recycling waste streams so that they are able to manage BCPP waste. The success of these policies would, in turn, rely on effective informational and motivational public campaigns and improved systems of labelling, where end-of-life instructions are efficiently communicated to citizens on packaging.

Limits to our study include taking intention as a proxy for behaviour. Gaps between the reported intention to perform a behaviour and the subsequent performance of that behaviour are well-established (referred to as the intention-behaviour gap) [69,70]. Our results should be interpreted with this in mind.

The demographic information of participants was not collected, which would have helped evaluate the likely generalisability of the results. The study is likely to show self- 
selection bias, whereby those who already engage in or are interested in composting were more likely to take part. While our results provide insight into behavioural influences, further studies are required to replicate the findings and assess their generalisability to other populations. For instance, it would be useful to explore how behavioural influences manifest within various consumer segments. More scientific research is needed to identify labelling systems that communicate packaging information more effectively, informed by knowledge about product design. Areas to address include the sustainability information citizens want on packaging, and whether this influences the extent to which they perceive the packaging to have environmental benefits and/or their purchasing behaviour. Research is needed to clarify which packaging or design features best communicate the correct disposal actions required by the end user, and whether they increase the correct disposal of BCPP. Acknowledging the role of other key actors in reducing plastic waste, further research into the factors influencing industry-level behaviour is needed. While there are some examples of such research being conducted e.g., within the horticultural sector [71], further industry-level behavioural investigations will be necessary for designing effective strategies that enable the transition to a circular plastics economy.

\section{Conclusions}

Successfully introducing BCPP into the market is not without its challenges, relying not only on technological innovation, but also on interventions that change human behaviour. Our paper provides a methodological framework for identifying influences on behaviour(s) that can aid in designing interventions more likely to be effective at achieving the desired behaviour change. Our methodology was specifically applied to understanding influences on citizens' BCPP purchases, which is important for enabling BCPP's environmental benefits. The practical usefulness of our study includes the detailing of a method that can be adapted by other researchers and practitioners, serving as a template for understanding a variety of environmentally significant behaviours and as a foundation for designing interventions that sustain environmental health.

Although limited to a UK context, our results have valuable implications for policy and intervention design. Our study reveals widespread public misunderstanding of the terms used to label BCPP, leading to confusion and mistrust towards packaging claims. Interventions will therefore need to reduce skepticism over environmental claims of packaging and ambiguity concerning the labels biodegradable and compostable. Based on prior research and the present findings, we suggest designing packaging based on usercentred needs for transparency. These include improving information on the source of the packaging material, how the packaging waste is processed, and how to dispose of the packaging. These changes, however, will not be sufficient unless facilities for local BCPP waste collection and processing are increased. To achieve this, we suggest policies that focus on improving the current waste infrastructure e.g., potentially adapting existing food waste management streams to accommodate compostable plastics.

Further research is needed to assess the generalisability of our findings to other contexts, and to investigate how packaging design can be used to promote environmentally conscious purchasing and waste management behaviours amongst citizens. Additional studies measuring actual behaviour as opposed to behavioural proxies will help promote the conclusiveness of results.

Supplementary Materials: The Thematic Codebook and Data Saturation Table are available online at https: / / www.mdpi.com/2071-1050/13/3/1463/s1, Table S1: Thematic Codebook, Table S2: Data Saturation Table.

Author Contributions: Conceptualization, A.L.A. and M.M.; Formal analysis, A.L.A.; Funding acquisition, M.M.; Investigation, A.L.A.; Methodology, A.L.A., F.L., and S.M.; Project administration, A.L.A.; Supervision, F.L., S.M., and M.M.; Validation, F.L.; Visualization, A.L.A.; Writing-original draft, A.L.A.; Writing-review \& editing, A.L.A., F.L., S.M., and M.M. All authors have read and agreed to the published version of the manuscript. 
Funding: This research was funded by EPSRC and UKRI, under grant EP/S024883/1.

Institutional Review Board Statement: The study was conducted according to the guidelines of the Declaration of Helsinki, and approved by the Ethics Committee of University College London (Project ID/Title: 16747/001: Big Compost Experiment, GDPR no. Z6364106/2019/10/109, approved 29 October 2019).

Informed Consent Statement: Informed consent was obtained from all subjects involved in the study.

Data Availability Statement: The data presented in this study are openly available via Open Science Framework at https:/ / doi.org/10.17605/OSF.IO/F7JNS.

Acknowledgments: We would like to thank Danielle Purkiss (danielle.purkiss@ucl.ac.uk) at the UCL Plastic Waste Innovation Hub for developing the Big Compost Experiment project and providing us with the data used in this study.

Conflicts of Interest: The authors declare no conflict of interest.

\section{Abbreviation \\ BCPP biodegradable and compostable plastic packaging}

\section{References}

1. PlasticsEurope. Plastics-The Facts 2019: An Analysis of European Plastics Production, Demand and Waste Data. Available online: https:/ / www.plasticseurope.org/application/files/9715/7129/9584/FINAL_web_version_Plastics_the_facts2019_14 102019.pdf (accessed on 26 June 2020).

2. Andrady, A.L.; Neal, M.A. Applications and societal benefits of plastics. Philos. Trans. R. Soc. B Biol. Sci. 2009, 364, 1977-1984. [CrossRef] [PubMed]

3. Barlow, C.; Morgan, D. Polymer film packaging for food: An environmental assessment. Resour. Conserv. Recycl. 2013, 78, 74-80. [CrossRef]

4. Humbert, S.; Rossi, V.; Margni, M.; Jolliet, O.; Loerincik, Y. Life cycle assessment of two baby food packaging alternatives: Glass jars vs. plastic pots. Int. J. Life Cycle Assess. 2009, 14, 95-106. [CrossRef]

5. Campani, T.; Baini, M.; Giannetti, M.; Cancelli, F.; Mancusi, C.; Serena, F.; Marsili, L.; Casini, S.; Fossi, M.C. Presence of plastic debris in loggerhead turtle stranded along the Tuscany coasts of the Pelagos Sanctuary for Mediterranean Marine Mammals (Italy). Mar. Pollut. Bull. 2013, 74, 225-230. [CrossRef] [PubMed]

6. Galgani, F.; Hanke, G.; Maes, T. Global distribution, composition and abundance of marine litter. In Marine Anthropogenic Litter; Springer: Cham, The Netherlands, 2015; pp. 29-56. [CrossRef]

7. Browne, M.A.; Crump, P.; Niven, S.J.; Teuten, E.; Tonkin, A.; Galloway, T.; Thompson, R. Accumulation of microplastic on shorelines woldwide: Sources and sinks. Environ. Sci. Technol. 2011, 45, 9175-9179. [CrossRef]

8. Rochman, C.M.; Hoh, E.; Kurobe, T.; Teh, S.J. Ingested plastic transfers hazardous chemicals to fish and induces hepatic stress. Sci. Rep. 2013, 3, 3263. [CrossRef]

9. Wilcox, C.; Mallos, N.J.; Leonard, G.H.; Rodriguez, A.; Hardesty, B.D. Using expert elicitation to estimate the impacts of plastic pollution on marine wildlife. Mar. Policy 2016, 65, 107-114. [CrossRef]

10. Chae, Y.; An, Y.-J. Current research trends on plastic pollution and ecological impacts on the soil ecosystem: A review. Environ. Pollut. 2018, 240, 387-395. [CrossRef]

11. Kosuth, M.; Mason, S.A.; Wattenberg, E.V. Anthropogenic contamination of tap water, beer, and sea salt. PLoS ONE 2018, 13, e0194970. [CrossRef]

12. Karami, A.; Golieskardi, A.; Choo, C.K.; Larat, V.; Galloway, T.S.; Salamatinia, B. The presence of microplastics in commercial salts from different countries. Sci. Rep. 2017, 7, 46173. [CrossRef]

13. Miranda, D.d.A.; de Carvalho-Souza, G.F. Are we eating plastic-ingesting fish? Mar. Pollut. Bull. 2016, 103, 109-114. [CrossRef] [PubMed]

14. Rochman, C.M.; Tahir, A.; Williams, S.L.; Baxa, D.V.; Lam, R.; Miller, J.T.; Teh, F.-C.; Werorilangi, S.; Teh, S.J. Anthropogenic debris in seafood: Plastic debris and fibers from textiles in fish and bivalves sold for human consumption. Sci. Rep. 2015, 5, 14340. [CrossRef] [PubMed]

15. Geyer, R.; Jambeck, J.R.; Law, K.L. Production, use, and fate of all plastics ever made. Sci. Adv. 2017, 3, e1700782. [CrossRef] [PubMed]

16. WRAP. Plastics: Market Situation Report 2019. Available online: https://www.wrap.org.uk/sites/files/wrap/WRAP_Plastics_ market_situation_report.pdf (accessed on 23 September 2020).

17. Niaounakis, M. Recycling of Flexible Plastic Packaging; William Andrew: Amsterdam, The Netherlands, 2019; ISBN 978-0-12-816335-1. 
18. Aparsi, T.D.; Chau, C.; Chandler, K.; Dobrijevic, D.; Hailes, H.; Leipold, L.; Lettieri, P.; Medda, F.; Michie, S.; Miodownik, M.; et al. Biodegradable plastics: Part of the solution or part of the problem? In Creative Circular Economy Approaches to Eliminate Plastics Waste, Proceedings of the Plastics Research and Innovation Fund Conference, Online, Sheffield, UK, 8-9 June 2020; UK Circular Plastics Network: Hull, UK, 2020; pp. 52-61.

19. Folino, A.; Karageorgiou, A.; Calabrò, P.S.; Komilis, D. Biodegradation of Wasted Bioplastics in Natural and Industrial Environments: A Review. Sustainability 2020, 12, 6030. [CrossRef]

20. Folino, A.; Fazzino, F.; Komilis, D. Preliminary evaluation of the anaerobic biodegradability of three biobased materials used for the production of disposable plastics. J. Hazard. Mater. 2020, 390, 121653. [CrossRef]

21. Hottle, T.A.; Bilec, M.M.; Landis, A.E. Biopolymer production and end of life comparisons using life cycle assessment. Resour. Conserv. Recycl. 2017, 122, 295-306. [CrossRef]

22. Rossi, V.; Cleeve-Edwards, N.; Lundquist, L.; Schenker, U.; Dubois, C.; Humbert, S.; Jolliet, O. Life cycle assessment of end-of-life options for two biodegradable packaging materials: Sound application of the European waste hierarchy. J. Clean. Prod. 2015, 86, 132-145. [CrossRef]

23. De Marchi, E.; Pigliafreddo, S.; Banterle, A.; Parolini, M.; Cavaliere, A. Plastic packaging goes sustainable: An analysis of consumer preferences for plastic water bottles. Environ. Sci. Policy 2020, 114, 305-311. [CrossRef]

24. WRAP. Consumer Attitudes to Biopolymers. Available online: https://www.wrap.org.uk/sites/files/wrap/Consumer\%20 attitude \%20to\%20biopolymers\%20report\%20final\%206th\%20Sep\%2007.pdf (accessed on 26 June 2020).

25. Dilkes-Hoffman, L.; Ashworth, P.; Laycock, B.; Pratt, S.; Lant, P. Public attitudes towards bioplastics-knowledge, perception and end-of-life management. Resour. Conserv. Recycl. 2019, 151, 104479. [CrossRef]

26. Taufik, D.; Reinders, M.J.; Molenveld, K.; Onwezen, M.C. The paradox between the environmental appeal of bio-based plastic packaging for consumers and their disposal behaviour. Sci. Total Environ. 2020, 705, 135820. [CrossRef]

27. Michie, S.; Atkins, L.; West, R. The behaviour change wheel. In A Guide to Designing Interventions, 1st ed.; Silverback Publishing: London, UK, 2014; pp. 1003-1010. ISBN 978-1-912141-00-5.

28. Michie, S.; Van Stralen, M.M.; West, R. The behaviour change wheel: A new method for characterising and designing behaviour change interventions. Implement. Sci. 2011, 6, 42. [CrossRef] [PubMed]

29. Hedin, B.; Katzeff, C.; Eriksson, E.; Pargman, D. A systematic review of digital behaviour change interventions for more sustainable food consumption. Sustainability 2019, 11, 2638. [CrossRef]

30. Graça, J.; Godinho, C.A.; Truninger, M. Reducing meat consumption and following plant-based diets: Current evidence and future directions to inform integrated transitions. Trends Food Sci. Technol. 2019, 91, 380-390. [CrossRef]

31. Addo, I.B.; Thoms, M.C.; Parsons, M. Barriers and drivers of household water-conservation behavior: A profiling approach. Water 2018, 10, 1794. [CrossRef]

32. Gainforth, H.L.; Sheals, K.; Atkins, L.; Jackson, R.; Michie, S. Developing interventions to change recycling behaviors: A case study of applying behavioral science. Appl. Environ. Educ. Commun. 2016, 15, 325-339. [CrossRef]

33. The Big Compost Experiment. Available online: www.bigcompostexperiment.org.uk (accessed on 16 November 2020).

34. Silvertown, J. A new dawn for citizen science. Trends Ecol. Evol. 2009, 24, 467-471. [CrossRef]

35. Bonney, R.; Shirk, J.L.; Phillips, T.B.; Wiggins, A.; Ballard, H.L.; Miller-Rushing, A.J.; Parrish, J.K. Next steps for citizen science. Science 2014, 343, 1436-1437. [CrossRef]

36. Shirk, J.L.; Ballard, H.L.; Wilderman, C.C.; Phillips, T.; Wiggins, A.; Jordan, R.; McCallie, E.; Minarchek, M.; Lewenstein, B.V.; Krasny, M.E. Public participation in scientific research: A framework for deliberate design. Ecol. Soc. 2012, 17, 29. [CrossRef]

37. UCL. Plastic Waste Innovation Hub. Available online: https:/ / www.plasticwastehub.org.uk/ (accessed on 21 April 2020).

38. Organic, G. Compostable Packaging; How Well Does It Live Up to Its Claim? Available online: https:/ / www.gardenorganic.org. uk/compostable-packaging-how-well-does-it-live-its-claim (accessed on 5 January 2020).

39. Web, S.F. What Is the Soil Food Web? Available online: https:/ /www.soilfoodweb.com/how-it-works/ (accessed on 5 January 2020).

40. Johnston, M.P. Secondary data analysis: A method of which the time has come. Qual. Quant. Methods Libr. 2017, 3, 619-626.

41. McGowan, L.J.; Powell, R.; French, D.P. How can use of the Theoretical Domains Framework be optimized in qualitative research? A rapid systematic review. Br. J. Health Psychol. 2020, 25, 677-694. [CrossRef]

42. Cane, J.; O'Connor, D.; Michie, S. Validation of the theoretical domains framework for use in behaviour change and implementation research. Implement. Sci. 2012, 7, 37. [CrossRef]

43. Atkins, L.; Francis, J.; Islam, R.; O'Connor, D.; Patey, A.; Ivers, N.; Foy, R.; Duncan, E.M.; Colquhoun, H.; Grimshaw, J.M. A guide to using the Theoretical Domains Framework of behaviour change to investigate implementation problems. Implement. Sci. 2017, 12, 77. [CrossRef] [PubMed]

44. Braun, V.; Clarke, V. Using thematic analysis in psychology. Qual. Res. Psychol. 2006, 3, 77-101. [CrossRef]

45. Maguire, M.; Delahunt, B. Doing a thematic analysis: A practical, step-by-step guide for learning and teaching scholars. All Irel. J. High. Educ. 2017, 9, 3351.

46. Nowell, L.S.; Norris, J.M.; White, D.E.; Moules, N.J. Thematic analysis: Striving to meet the trustworthiness criteria. Int. J. Qual. Methods 2017, 16, 1609406917733847. [CrossRef]

47. Faulkner, S.L.; Trotter, S.P. Data saturation. Int. Encycl. Commun. Res. Methods 2017, 1-2. [CrossRef]

48. Fusch, P.I.; Ness, L.R. Are we there yet? Data saturation in qualitative research. Qual. Rep. 2015, $20,1408$. 
49. Morse, J. Theoretical Saturation. In Encyclopedia of Social Science Research Methods; SAGE Publications: Thousand Oaks, CA, USA, 2004. [CrossRef]

50. Guest, G.; Namey, E.; Chen, M. A simple method to assess and report thematic saturation in qualitative research. PLoS ONE 2020, 15, e0232076. [CrossRef]

51. Nguyen, T.N.; Lobo, A.; Greenland, S. Pro-environmental purchase behaviour: The role of consumers' biospheric values. J. Retail. Consum. Serv. 2016, 33, 98-108. [CrossRef]

52. Barbarossa, C.; De Pelsmacker, P. Positive and negative antecedents of purchasing eco-friendly products: A comparison between green and non-green consumers. J. Bus. Ethics 2016, 134, 229-247. [CrossRef]

53. Albayrak, T.; Aksoy, Ş.; Caber, M. The effect of environmental concern and scepticism on green purchase behaviour. Mark. Intell. Plan. 2013, 31, 27-39. [CrossRef]

54. Heo, J.; Muralidharan, S. What triggers young Millennials to purchase eco-friendly products?: The interrelationships among knowledge, perceived consumer effectiveness, and environmental concern. J. Mark. Commun. 2019, 25, 421-437. [CrossRef]

55. Salazar, H.A.; Oerlemans, L.; van Stroe-Biezen, S. Social influence on sustainable consumption: Evidence from a behavioural experiment. Int. J. Consum. Stud. 2013, 37, 172-180. [CrossRef]

56. Orzan, G.; Cruceru, A.F.; Bălăceanu, C.T.; Chivu, R.-G. Consumers' Behavior Concerning Sustainable Packaging: An Exploratory Study on Romanian Consumers. Sustainability 2018, 10, 1787. [CrossRef]

57. Thøgersen, J.; Haugaard, P.; Olesen, A. Consumer responses to ecolabels. Eur. J. Mark. 2010. [CrossRef]

58. Leire, C.; Thidell, A. Product-related environmental information to guide consumer purchases-A review and analysis of research on perceptions, understanding and use among Nordic consumers. J. Clean. Prod. 2005, 13, 1061-1070. [CrossRef]

59. Nordin, N.; Selke, S. Social aspect of sustainable packaging. Packag. Technol. Sci. 2010, 23, 317-326. [CrossRef]

60. WRAP. Considerations for Compostable Plastic Packaging. Available online: https://www.wrap.org.uk/sites/files/wrap/ Considerations-for-compostable-plastic-packaging.pdf (accessed on 16 November 2020).

61. Parliament, E. Directive 2008/98/EC of the European Parliament and of the Council of 19 November 2008 on waste and repealing certain Directives. Off. J. Eur. Union 2008, 312, 3-30.

62. Rokka, J.; Uusitalo, L. Preference for green packaging in consumer product choices-Do consumers care? Int. J. Consum. Stud. 2008, 32, 516-525. [CrossRef]

63. Biswas, A.; Roy, M. Green products: An exploratory study on the consumer behaviour in emerging economies of the East. J. Clean. Prod. 2015, 87, 463-468. [CrossRef]

64. Guyader, H.; Ottosson, M.; Witell, L. You can't buy what you can't see: Retailer practices to increase the green premium. J. Retail. Consum. Serv. 2017, 34, 319-325. [CrossRef]

65. Barr, S. Factors influencing environmental attitudes and behaviors: A UK case study of household waste management. Environ. Behav. 2007, 39, 435-473. [CrossRef]

66. Hahladakis, J.N.; Purnell, P.; Iacovidou, E.; Velis, C.A.; Atseyinku, M. Post-consumer plastic packaging waste in England: Assessing the yield of multiple collection-recycling schemes. Waste Manag. 2018, 75, 149-159. [CrossRef] [PubMed]

67. Agency, E.E. Biodegradable and Compostable Plastics: Challenges and Opportunities. Available online: https://bbia.org.uk/wpcontent/uploads/2020/09/biodegradable-and-compostable-plastics-challenges-EEA.pdf (accessed on 24 September 2020).

68. Nemat, B.; Razzaghi, M.; Bolton, K.; Rousta, K. The Potential of Food Packaging Attributes to Influence Consumers' Decisions to Sort Waste. Sustainability 2020, 12, 2234. [CrossRef]

69. Webb, T.L.; Sheeran, P. Does changing behavioral intentions engender behavior change? A meta-analysis of the experimental evidence. Psychol. Bull. 2006, 132, 249. [CrossRef]

70. Bernardes, J.P.; Ferreira, F.; Marques, A.D.; Nogueira, M. “Do as I say, not as I do"-A systematic literature review on the attitude-behaviour gap towards sustainable consumption of Generation Y. Mater. Sci. Eng. 2018, 459, 012089. [CrossRef]

71. Galati, A.; Sabatino, L.; Prinzivalli, C.S.; D'Anna, F.; Scalenghe, R. Strawberry fields forever: That is, how many grams of plastics are used to grow a strawberry? J. Environ. Manag. 2020, 276, 111313. [CrossRef] 